\title{
ALTERAÇÕES CAUSADAS POR AVULSÃO NO RIO TAQUARI, NO PANTANAL MATO-GROSSENSE
}

\section{Changes makes by avulsion in Rio Taquari, in the Pantanal Mato-Grossense}

\author{
Mercedes Abid MERCANTE 1 \\ Sílvio Jacks dos Anjos GARNÉS² \\ Luiz Antônio PAIVA 3 \\ Eva Teixeira dos SANTOS 4 \\ Albana Xavier NOGUEIRA 5
}

\section{RESUMO}

No leque aluvial do Rio Taquari, no Pantanal Mato-Grossense, registram-se processos de dinâmica fluvial, os quais ocasionam o fenômeno de avulsão, com a mudança de direção do Rio Taquari, que altera o mosaico de paisagens e compromete a vida dos moradores residentes em colônias, a navegação e as atividades econômicas. Os dados são provenientes de informações extraídas de imagens de satélites e de trabalho de campo, e os resultados indicam que a avulsão é um processo natural, porém intensificado nos últimos anos por ações antrópicas. Tem como exemplo socioambiental uma colônia de moradores, e as recomendações objetivam auxiliar os programas de planejamento para a área do baixo curso do Rio Taquari, a qual apresenta riscos de novas mudanças do rio.

\section{Palavras-chave}

Pantanal; Rio Taquari; avulsão.

\begin{abstract}
In the alluvial cone of the Taquari River, in Pantanal MatoGrossense, it is registered the dynamic fluvial process, which causes the avulsion phenomenon with the changes in the Taquari riverbed that modifies the mosaic scenery and compromise specially the lifes of people who lives in settlements, the shipping and the economic activities. Data are proceeding from information of satellite pictures and field research, and indicate that avulsion is a natural process, they thought, it increased by antropic actions in the last years. Like an environmental example, there is the Reparian Settlements and the recommendations objectify to help the planning programs for the Taquari River low flow areas, which shows risks for new water flow changes.
\end{abstract}

Key words

Pantanal; Taquari River; avulsion.

1 Professora Dra. - Mestrado em Meio Ambiente e Desenvolvimento Regional - Universidade para o Desenvolvimento do Estado e da Região do Pantanal - UNIDERP.

2 Professor Dr. - Mestrado em Meio Ambiente e Desenvolvimento Regional - UNIDERP.

3 Professor MSc. - UNIDERP.

4 Professora MSc - UNIDERP.

5 Professora Dra. - Mestrado em Meio Ambiente e Desenvolvimento Regional - UNIDERP. 
MERCANTE, M. A. et al. Alterações causadas por avulsão no Rio Taquari...

\section{INTRODUÇÃO}

Até a metade da década de 1970 , os estudos sobre o Pantanal Mato-Grossense raramente abordavam os processos da geomorfologia fluvial relativos à dinâmica do leque aluvial do Rio Taquari, no estado de Mato Grosso do Sul. Entrementes, as contribuições científicas recentes tornaram-se mais esclarecedoras da complexidade e da instabilidade decorrentes dos processos de avulsão, abandono e abertura de novos canais e assoreamento que acontecem no leito do Rio Taquari. Trata-se de uma série de estudos que, por diferentes roteiros metodológicos, buscam as explicações para a dinâmica dos processos geomorfológicos (BRAUN, 1977; TRICART, 1982; AB'SABER, 1988 e 1989; CREPANI e SANTOS, 1994; ASSINE e SOARES, 1998; QUEIRÓS NETO et al., 1998; PADOVANI, 2001; SOARES et al., 2003; ABDON, 2004; QUEIRÓS NETO, 2004; ASSINE et al., 2005; SANTOS E MERCANTE, 2005).

A paisagem do macroleque aluvial do Rio Taquari apresenta arranjos de sedimentação diversificados, onde coexistem as formas recentes e as reliquiares, sendo que estas são resultantes do somatório de processos históricos cumulativos no corpo sedimentário, que remontam ao período Pleistoceno, e testemunham a formação de feições geomórficas decorrentes de formações aluviais e eólicas (ALMEIDA, 1964; TRICART, 1982; AB'SABER, 1988; SOARES et al., 2003; ASSINE, 2005).

Nos últimos trinta anos, ocorreram mudanças do leito no baixo curso do Rio Taquari (PADOVANI, 2001) e as informações sobre as conseqüências dessas transformações, tanto para as comunidades tradicionais residentes, nas pequenas colônias (MORETTI, 1996; CURADO, 2004) como para os grandes proprietários, têm contribuído para confirmar que as mudanças paisagísticas recentes causaram impactos de grande magnitude (AB'SABER, 1989; QUEIRÓS
NETO, 2004) e assegurar que a Bacia do Rio Taquari é um laboratório de temas hidrogeomorfológicos emergentes, para trabalhar a perseguida interface natureza e sociedade.

Em decorrência das conseqüências do fenômeno de avulsão, a mídia passa a divulgar reportagens acerca da problemática socioambiental, reportando-se ao processo como conseqüência da ação antrópica no alto curso do rio, sobretudo no planalto circundante, e veicula as conseqüências desse fato, no leque aluvial dentro da depressão pantaneira, como o Pantanal que está fora do mapa, no qual os colonos viram favelados e pantaneiros, sem terra.

Este estudo parte dos pressupostos de que o Rio Taquari, ao alcançar o leque aluvial e à medida que avança para jusante, corre em compartimentos geomorfológicos diferentes, sendo o primeiro um cinturão de meandros, e o segundo o lobo ativo, nos quais os processos da dinâmica fluvial ocasionam a ocorrência do fenômeno de avulsão; por conseguinte, esses acontecimentos resultam em mudanças e aberturas de novos caminhos fluviais, que provocam inundações e refletem no modo de vida dos pantaneiros, que sobrevivem com forte dependência do Rio Taquari. Tem como objetivo disponibilizar informações como subsídios para a busca de alternativas de desenvolvimento auto-sustentável, para uma região da planície de coalescência detrítico-aluvial do Pantanal, de alta fragilidade ambiental, a qual está sendo preenchida por sedimentos quaternários.

A área da pesquisa está inserida no compartimento geomorfológico do lobo distributário e ativo do leque aluvial, onde ocorre com freqüência o fenômeno de avulsão, com a mudança do leito do Rio Taquari. Especificamente, a análise pontual dos reflexos socioambientais tem como pano de fundo a Colônia São Domingos, pertencente ao município de Corumbá, no estado de Mato Grosso do Sul. (Figura 1) 
FIGURA 1: LOCALIZAÇÃO DA ÁREA DE ESTUDO NO LOBO ATIVO DO LEQUE ALUVIAL DO RIO TAQUARI NO PANTANAL SUL-MATO-GROSSENSE
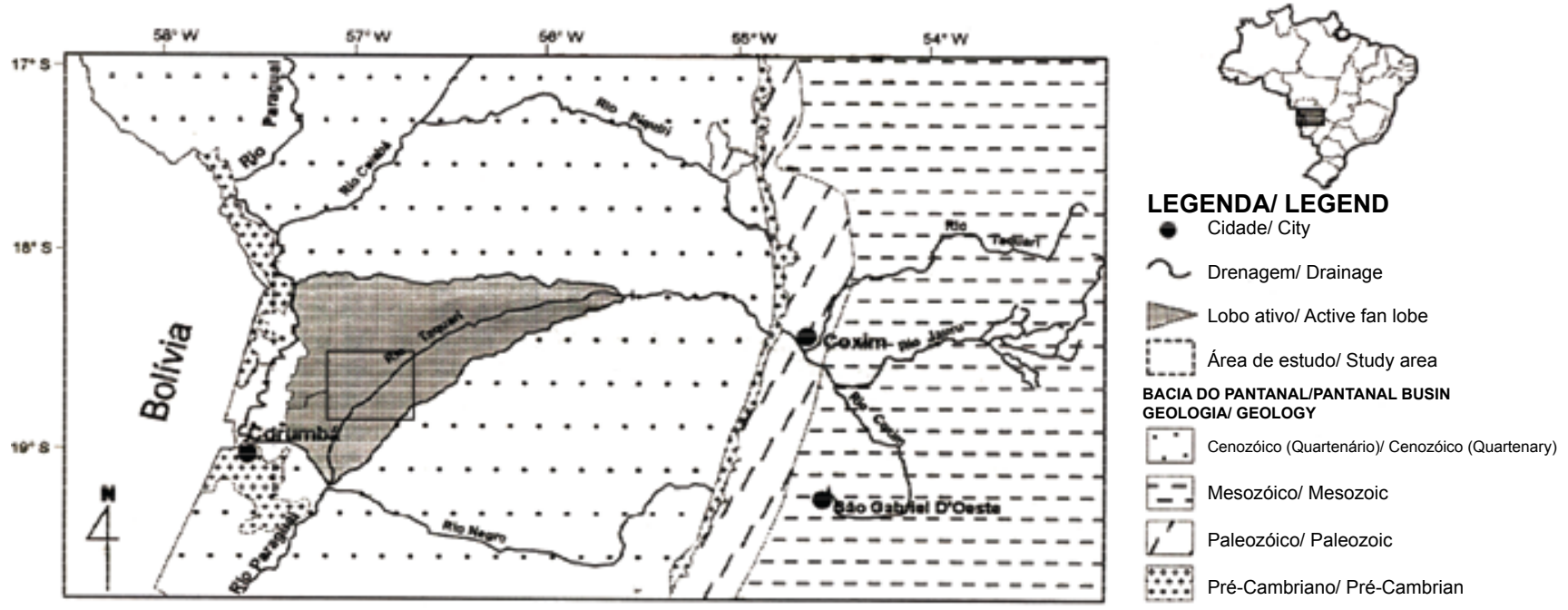

Por meio de uso de técnicas de geoprocessamento com base em imagens de satélite, foi possível delimitar o lobo ativo (active fan lobe) no interior do macroleque aluvial do Rio Taquari, e as demais informações foram obtidas das seguintes fontes:

- nas cartas topográficas do DSG na escala 1:100.00, utilizando-se a Folha SE. 21-2 A-IV (Paraguai Mirim), a Folha SE.21-2 A-IV (Porto Rolon) e a Folha SE. 21.Z-C-1 (Nhecolândia);

- em fotografias aéreas na escala 1:60.000 (USAF, 1966) e imagens de satélite Landsat TM, composição colorida das bandas 3, 4, 5 e órbita 226/73;

- realização de trabalhos de campo na área de estudo, em julho de 2004, para a obtenção dos dados de coordenadas geográficas, dos pontos de avulsão, com o uso de receptores GPS de navegação, ao nível do terreno e para a coleta de informações por meio de entrevistas pelo uso de técnicas de pesquisa oral;

- dados coletados em documentários de TV e noticiários de jornais.

O suporte teórico alicerça-se em abordagens que explicam a dinâmica da paisagem no pantanal (ALMEIDA, 1945; TRICART, 1982; AB'SABER, 1988) nos sistemas dos leques aluviais (CHRISTOFOLETTI, 1988, ASSINE e SOARES, 1998; ASSINE et al. 2005).

Apóia-se nas concepções de análise que buscam o entendimento das relações das sociedades humanas com a natureza, como recomenda Ross (2003, p. 352). Dentro dessa perspectiva, os estudos têm sempre como referenciais uma determinada sociedade (comunidade) que vive em um território, onde desenvolve suas atividades, com maior ou menor grau de complexidade, em função da intensidade dos vínculos internos e externos que mantêm no plano cultural, social e econômico.

\section{CONSIDERAÇÕES SOBRE O SISTEMA DO RIO TAQUARI}

A bacia hidrográfica do Rio Taquari está localizada entre as latitudes de $17^{\circ}$ e $20^{\circ} \mathrm{S}$ e as longitudes de $53^{\circ}$ e $58^{\circ} \mathrm{W}$, abrangendo uma área de $65.023 \mathrm{~km}^{2}$, no conjunto da bacia do Rio Paraguai. O principal contribuinte dessa bacia é o rio de nome homônimo, que tem sua nascente no estado de Mato Grosso (900m de altitude) (Figura 2). 


\section{FIGURA 2: LOCALIZAÇÃO DA BACIA DO RIO TAQUARI NO ESTADO DE MATO GROSSO DO SUL. O MAPA INDICA AS UNIDADES DO ANFITEATRO EROSIVO NA PARTE DO PLANALTO E O GRANDE LEQUE ALUVIAL NA PLANÍCIE PANTANEIRA}

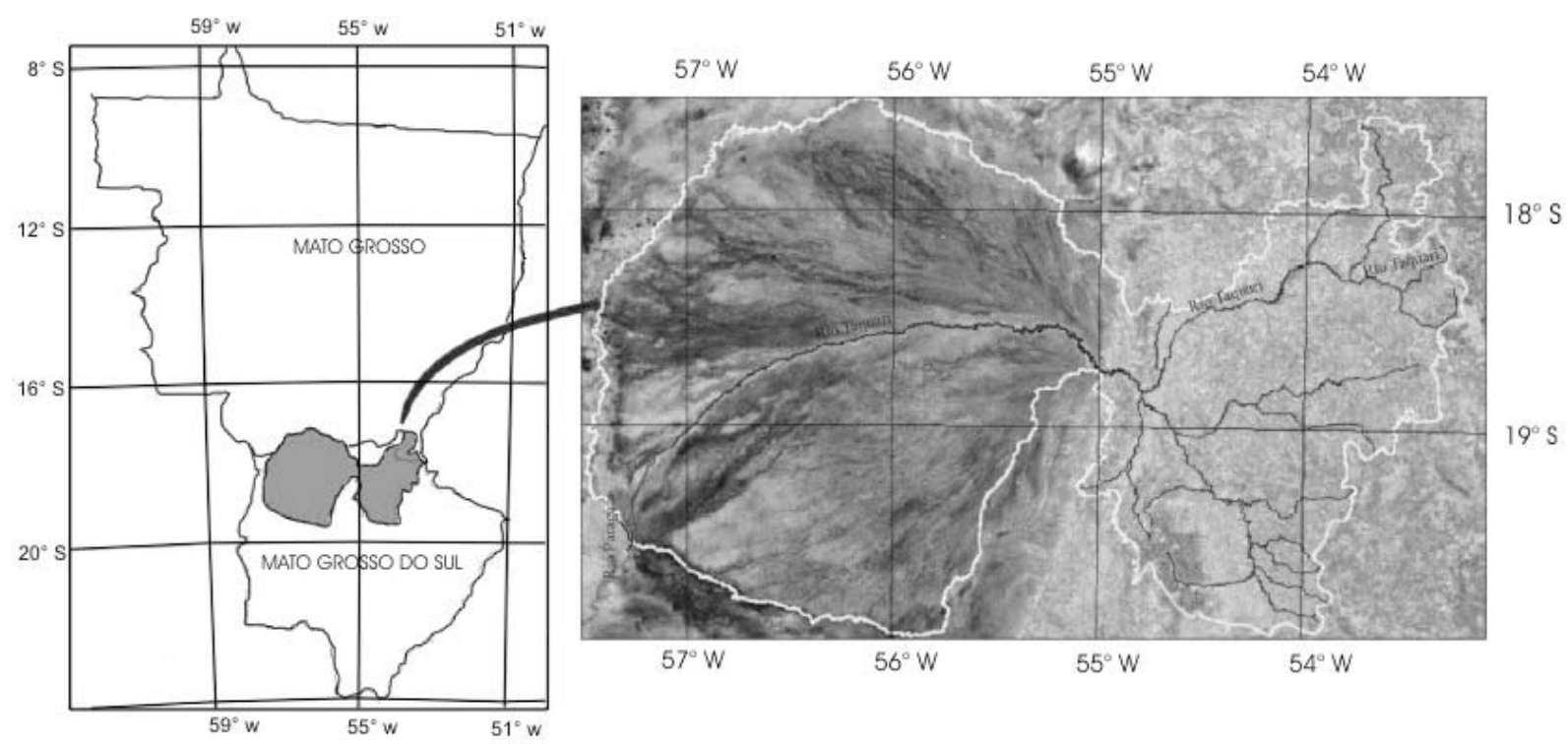

FONTE: Adaptado de ABDON, M. M. (2004).

A fragilidade dessa região deve-se à composição do sistema do Rio Taquari, que flui de uma região de terras mais altas para dentro de terras baixas da planície pantaneira. A região de planaltos, com altitudes que variam de 200 a 900 metros, faz parte do domínio morfoclimático dos cerrados. Os solos são em sua maioria arenosos e sujeitos a um clima estacional com concentração de chuvas de setembro a março. Nessas terras, os desmatamentos para implementação de pastagens e agricultura, sem considerar o ajuste da capacidade de suporte, vem causando vários problemas de desequilíbrios nas duas unidades geomorfológicas. Entre esses problemas, são mais evidentes os processos erosivos das terras altas do planalto e a transferência de grandes quantidades de sedimentos para o leque aluvial do Taquari.

\section{O LEQUE ALUVIAL DO RIO TAQUARI NO PANTANAL}

O leque aluvial do Rio Taquari é a feição mais notável na geomorfologia do Pantanal. Apresenta características sui generis, ora pela sua forma geométrica, notadamente circular e com diâmetro aproximado de $250 \mathrm{~km}$, ora pela sua extensão, ocupando uma área que abrange cerca de $50.000 \mathrm{~km}^{2}$, que compreende cerca de $36 \%$ da bacia detrítica quaternária do Pantanal, ora pela sua dinâmica sedimentar com a paisagem mutante, com a construção e o abandono de lobos deposicionais.

Um dos registros pioneiros sobre o leque aluvial do Rio Taquari foi o de Braun (1977), que delimitou como uma unidade geomórfica e abordou os primeiros parâmetros relacionados à sua formação com a ocorrência de um período de intensa erosão em condições paleoclimáticas e paleo-hidrográficas que remontam ao período do Pleistoceno. O autor evidencia que o cone é o resultado do processo erosivo da parte alta da bacia e a sua gênese corresponde a um enorme volume de areias que vêm acumulando há milhões de anos, cujo processo de deposição de sedimentos provoca a instabilidade do leito do rio principal, ocasionando alterações no seu conjunto.

Ab'Saber (1988) afirma que, para entender a gênese da bacia do Rio Taquari no Pantanal, é importante saber que, a partir da depressão tectônica terminal que envolveu 450 a 500 metros de sedimentação, em um período entre 13 mil e 23 mil anos, criaram-se enormes leques de areias dentro do Pantanal, em regime muito mais seco do que o de hoje. Esses compartimentos arenosos são os maiores leques aluviais do mundo, e no conjunto destaca-se o do Taquari.

Segundo o autor, o Rio Taquari desventrou o paleocone bem no centro do seu conjunto, que era muito alargado do sul para o norte. 
E nesse conjunto paisagístico o Rio Taquari, no Pantanal, corre no megaleque aluvial em dois compartimentos distintos: um na parte superior a jusante da cidade de Coxim, com aproximadamente $100 \mathrm{~km}$ de extensão, o rio divaga em inúmeros meandros, recolocando areias na frente. $E$, à medida que o rio avança e adentram no Pantanal, os meandros diminuem, os terraços perdem altura, de tal forma que, quando o rio alcança o segundo compartimento, especificamente no lobo ativo, os terraços praticamente desaparecem. Como conseqüências, mudam as características morfológicas, e o leque aluvial adquire novas feições, pois representa o principal sítio de sedimentação do Taquari. (ASSINE, 2005)

No lobo ativo, o canal do rio passa a ser anastomosado, com bifurcação dos mesmos, os quais divagam e interconectam-se na planície de inundação, muitas vezes contornando área com vegetação típica.

O leito do Rio Taquari nesses compartimentos torna-se instável na época das enchentes mais fortes e, com a elevação das águas, os diques marginais rompem, permitindo o extravasamento das águas pelos canais abertos, causando, por conseguinte, sérios problemas para as fazendas de criação de gado e às colônias de pequenos produtores, como São Domingos, Cedro, Miquelina, Bracinho e Rio Negro.

No lobo ativo, ocorre o fenômeno de avulsão fluvial, que, segundo Christofoletti (1988), é o deslocamento súbito no campo meândrico por um rio que segue um novo traçado. O canal fluvial muda bruscamente de direção e migra para os locais fora do domínio original do canal. O processo de mudança é registrado nos sistemas de leques aluviais, ou seja, ocorre a mudança de um canal em relação a um novo conseguido pelo rio, com o rompimento das margens dotadas de fragilidade.

A avulsão inicia-se com o rompimento do dique marginal e parte das águas fluviais passam a correr nas áreas mais baixas, no reverso do dique na planície de inundação, que ficam inundadas.

O pantaneiro e o ribeirinho reúnem o processo e a conseqüência do rompimento das margens dos rios, sob as designações de "bocas" para o ponto de rompimento e de "arrombados" para os canais que mudaram de direção e "margem mole", para os diques marginais dotados de fragilidade. A explicação é a mesma, o rio muda, ou seja, "arromba" a margem, num trecho em que a correnteza consegue romper o dique e adquire um novo traçado.

As alterações causadas pelas avulsões são intensas no lobo ativo, na sub-região dos Paiaguás, constituindo uma unidade de paisagem nas proximidades do local onde, no final de década de 1980 e início de 1990, ocorreu a mudança brusca de direção do Rio Taquari, conhecido como "Arrombado Zé da Costa". A constatação das mudanças do leito do Rio Taquari, na área delimitada para este estudo, foi obtida durante o trabalho de campo, e os pontos principais são (Figura 3):

- no local em que houve a mudança brusca de direção do Rio Taquari, conhecido como "Arrombado Zé da Costa" (latitude de 18²' $32^{\prime \prime}$ S e longitude $56^{\circ} 56^{\prime} 44^{\prime \prime} \mathrm{W}$ );

- no ponto de avulsão, denominado "arrombadão", que é uma ramificação do Arrombado Zé da Costa (latitude de $18^{\circ} 43^{\prime} 10^{\prime \prime} \mathrm{S}$ e longitude $\left.57^{\circ} 01^{\prime} 22^{\prime \prime} \mathrm{W}\right)$;

- Corixo São Domingos, no ponto de acesso à Colônia São Domingos (latitude 1842'05's e longitude $57^{\circ} 2 ' 38^{\prime \prime} \mathrm{W}$ );

- abertura de um canal de drenagem recente, pela ação do homem, com um metro de largura (latitude 18 $43^{\prime} 31^{\prime \prime} \mathrm{S}$ e longitude $\left.57^{\circ} 04^{\prime} 11^{\prime \prime} \mathrm{W}\right)$. 
FIGURA 3: PONTOS INDICADORES DE MUDANÇA DE PAISAGEM NO LOBO ATIVO DO LEQUE ALUVIAL, NA ÁREA DE ESTUDO

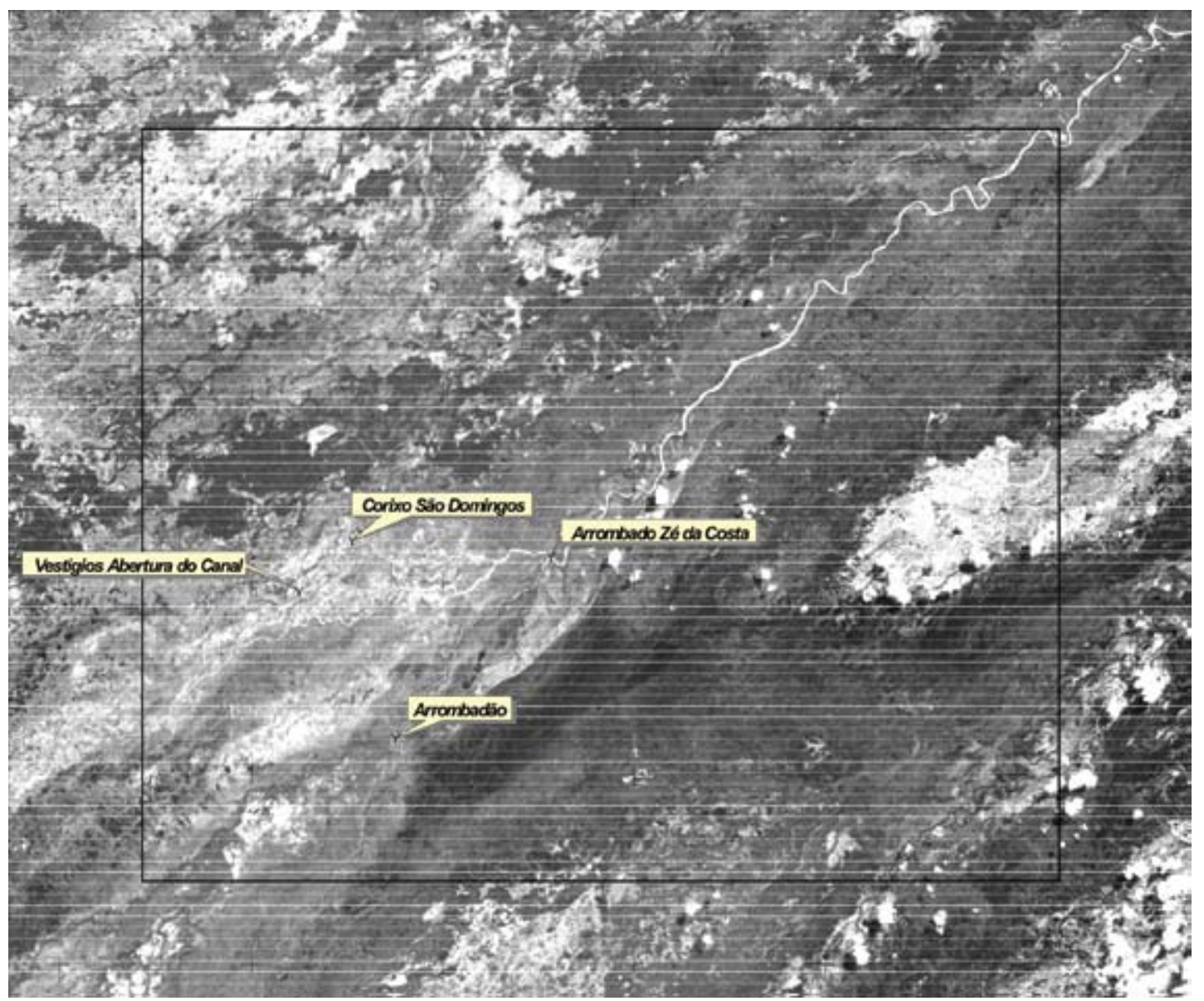

Com a mudança do Rio Taquari, na década de 1990, em conseqüência do rompimento da margem e da abertura do "Arrombado Zé da Costa", o rio passou a fluir para Noroeste, alcançando os canais do Rio Negrinho e do Rio Paraguai-Mirim, e passou a desaguar cerca de $30 \mathrm{~km}$ acima de sua antiga foz, no Rio Paraguai.

\section{A COLÔNIA SÃO DOMINGOS E AS VICISSITUDES DE UMA COMUNIDADE}

A Colônia São Domingos localiza-se cerca de 90 km da linha divisória Brasil-Bolívia, no leque aluvial do Taquari, e tornou-se uma comunidade aparentemente isolada, em virtude da ocorrência de avulsão do canal principal do Rio Taquari e da abertura de novos canais pelo rompimento das margens e dos diques marginais (arrombados).

A colônia foi instalada às margens do Corixo São Domingos, o qual representa a via de comunicação e acesso com o rio Taquari. O local de entrada para a colônia a partir do canal distributário do Arrombado Zé da Costa constitui um indicador das alterações ocorridas com a mudança da direção do rio.

Antes do processo de avulsão do Rio Taquari, as embarcações que partiam de Corumbá chegavam aos locais das Colônias por caminhos fluviais mais curtos que os atuais. A partir da cidade de Corumbá, atingia-se o Rio Taquari pelo rio Paraguai, porém, com a mudança do leito, agora é possível chegar ao Rio Taquari partindo do porto Corumbá no Rio Paraguai e adentrar pelo Rio Paraguai-Mirim. 
FIGURA 4: TRAÇADO DE NOVOS CANAIS, A PARTIR DO ROMPIMENTO DO DIQUE MARGINAL NO ARROMBADO ZÉ DA COSTA E A LOCALIZAÇÃO DA COLÔNIA SÃO DOMINGOS

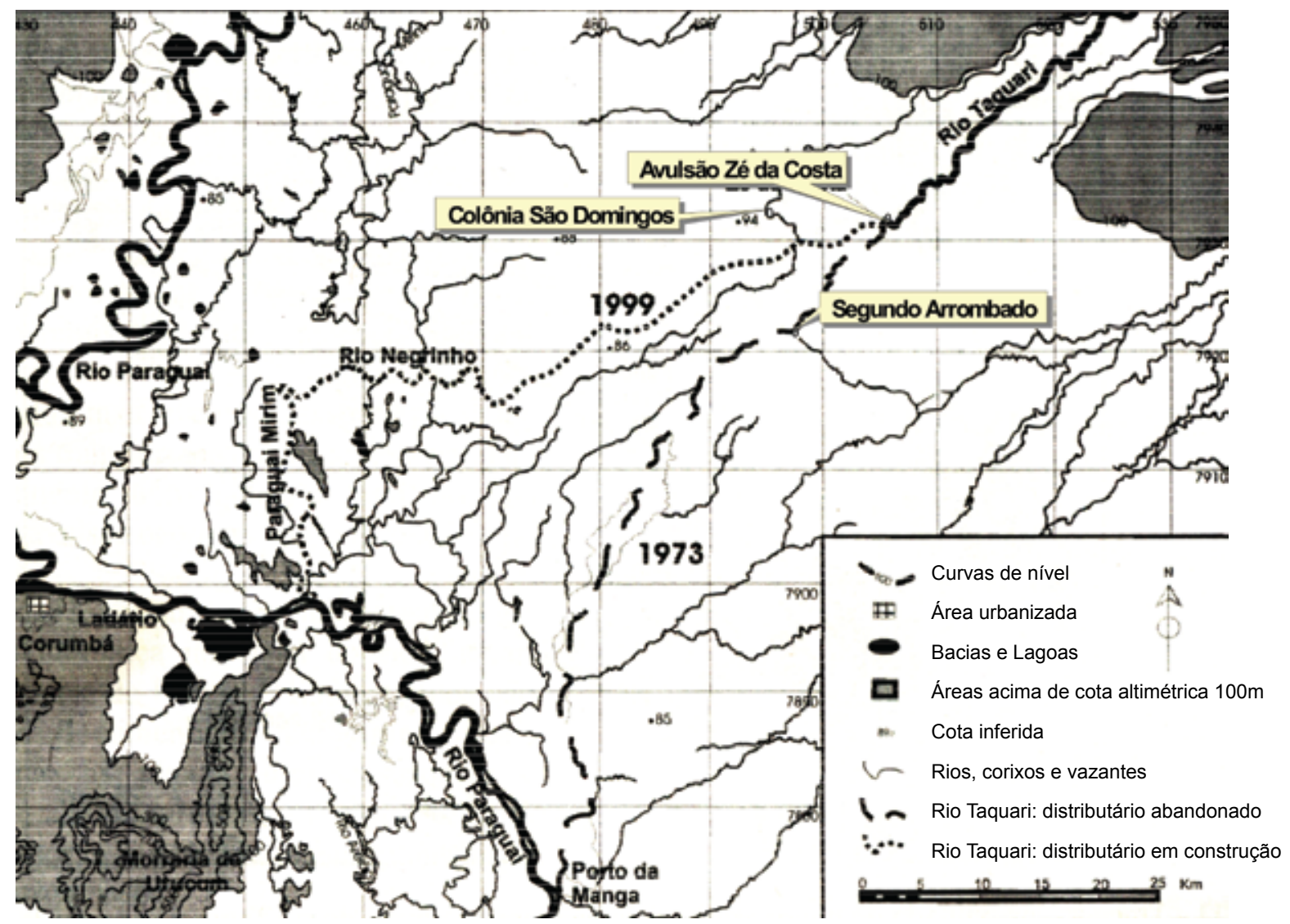

FONTE: Adaptado de PADOVANI, 2001.

A referida Colônia foi implantada numa porção de terra firme de pequena elevação métrica e com pequeno desnível topográfico, com o predomínio de um manto de sedimentos arenosos, que se acumulam nos cordões alongados e recobertos por formações de cerrados e acurizal.

Os moradores organizam-se no local em função dos compartimentos geomorfológicos locais. Os lugares preferenciais para a edificação de suas residências rudimentares são os cordões arenosos e mais elevados geralmente a um metro acima do nível de inundação máxima, que são denominadas regionalmente de "cordiIheiras", as quais apresentam topo relativamente plano, cobertas por vegetação com espécies do cerrado ou acuri (Schleeea phalerata), formadas por areias finas e soltas e inconsolidadas. As casas residenciais que abrigam os moradores e suas edificações rurais de apoio, como paiol, pequenos currais, galinheiros, moendas, escolas, igrejas e o centro comunitário, são construídas nas pequenas elevações de feições arredondadas existentes nas cordilheiras de até 0,5 metros de altura, denominadas localmente de "murunduns".

As demais feições geomórficas dão ao sítio da Colônia São Domingos uma característica sui generis. As formas são sinuosas e os arranjos locais lembram os paleodiques marginais de canais entrelaçados.

As áreas deprimidas são feições amplas, com declives voltados à zona mais baixa, coberta de gramíneas no período de estiagem. No período das cheias, essas áreas transformam-se em vazantes, ou seja, servem de escoamento superficial das águas.

Os recortes históricos sobre o povoamento da Colônia São Domingos são esparsos e inconsistentes e indicam que o processo de ocupação teve início a partir das décadas de 1920 e 1930, com as doações concedidas pelo marechal Cândido Rondon aos descendentes de populações tradicionais. 
MERCANTE, M. A. et al. Alterações causadas por avulsão no Rio Taquari...

A população mantém um forte vínculo com a dinâmica das águas. Os moradores herdaram dos índios guatós a relação com as águas e são hábeis navegadores em pequenas embarcações rústicas, movidas manualmente, com o uso de zingas. Os pequenos barcos feitos de troncos de árvores são utilizados como meio de transporte no interior da colônia e para a comunicação até o pequeno no porto na embocadura do Corixo São Domingos com o canal avulsionado do rio.

A vida na Colônia, associada às oscilações sazonais do Pantanal, não apresentou grandes alterações até os primeiros anos da década de 1970, quando era uma aglomeração da beira do corixo que, com a Colônia Bracinho situada na beira do Rio Taquari, formavam um conjunto que, juntamente, com outras, denominadas de Cedro, Rio Negro e Miquelina, pontilhavam a imensidão do baixo pantanal, todas dependentes de meios de circulação rudimentar de navegação fluvial e terrestre para o transporte da população e de sua produção.

A comunidade da Colônia São Domingos vivia quase exclusivamente integrada a uma economia rústica, servindo ao mercado regional de Corumbá. Os principais produtos explorados para a comercialização eram da fruticultura, com a produção de bananas e laranjas. Testemunhos de moradores locais certificam que o Rio Taquari era navegado por embarcações de médio porte, de sua embocadura no Rio Paraguai até a cidade de Coxim. No entanto, esse trecho, não é mais navegável com a mesma facilidade do início do século passado. Atualmente, é impossível navegar com as mesmas cargas de outrora, em virtude das dificuldades existentes pela presença de sedimentos depositados ao longo do leito fluvial, formando os bancos de areias.

A economia local, envolvendo os pequenos agricultores, era marcadamente de subsistência (milho, arroz e feijão), além da criação de gado e de pequenos animais. A pesca, apesar de praticada, aparece como atividade secundária. Constituía-se num aglomerado humano de gente do extremo-oeste do Brasil, trabalhando na beira do corixo que dá o nome àquele vilarejo, com uma relação tradicional de convivência com a dinâmica fluvial e um esforço coletivo para evitar a abertura de novos canais que ocasionam o início do processo de mudança do canal do rio.

Hoje é um aglomerado humano que, na intenção de evitar o avanço das águas com a ocorrência de novas avulsões, realizam um trabalho coletivo para impedir que as águas tragam transtornos aos fazendeiros e agricultores familiares. Procuram fechar os pontos vulneráveis dos diques marginais com barreiras, na tentativa de assegurar que o rio não inunde suas propriedades e não provoque o abandono das suas terras e, conseqüentemente, a migração para a periferia de Corumbá e outras cidades.

A Colônia São Domingos, antes da grande cheia do Pantanal, ocorrida no final da década de 1980, possuía um sítio com aproximadamente 3.500 hectares situados a escapo das águas, numa área que só eventualmente era ameaçada por grandes inundações do Rio Taquari. Atualmente, cerca de 2.000 hectares dessa área estão submersos, afetados pela inundação causada pelas águas que fluem de um dos canais provenientes do rompimento da margem esquerda do Rio Taquari, denominado "Arrombado Zé da Costa".

A população residente no local está ligada a dois segmentos de tradições. Uma amarrada à memória evanescente dos tempos em que o lugarejo situava-se no local mais seco e livre de inundações prolongadas. Outra, relacionada ao esforço de sobreviver no leque aluvial do baixo Taquari, com os problemas advindos das grandes cheias e com a expectativa permanente da ocorrência de novos fenômenos de avulsão.

Isolado no extenso leque aluvial, o homem pantaneiro aprendeu a respeitar o domínio da natureza, a dinâmica das águas e a sua importância para a vida nesse ambiente, convive com o fenômeno dos "arrombados", compreendendo que a instabilidade do Rio Taquari está atrelada aos processos do próprio rio.

Atualmente, vivem na Colônia São Domingos 42 famílias ainda fortemente ligadas à vida local. Porém, as sucessivas alterações ocorridas no leito do Rio Taquari, nas últimas duas décadas do século passado, promoveram profundas transformações socioambientais e econômicas que conduzem os meios de comunicação a veicularem notícias sobre a existência de um Pantanal que não está no mapa (Folha de S. Paulo, 1997) ou referir-se ao problema do Rio Taquari como um rio sem vida (Programa Globo Repórter, 2003).

\section{CONSIDERAÇÕES FINAIS}

A evolução do quadro paisagístico da mais espessa bacia de sedimentação quaternária do país é decorrente de mudanças paleoclimáticas, que modificam o Pantanal desde o Pleistoceno, com a formação de leques aluviais arenosos, que se constituem em ambientes complexos e da alta fragilidade ambiental, tal como acontece no macroleque aluvial do Taquari.

Além de frágil devido à paisagem psamítica, existem fatos referentes à alteração no leque aluvial, sobretudo pelos registros de mudanças bruscas no baixo curso do Rio Taquari, no lobo ativo do leque, ocasionadas pelo processo natural da avulsão. 
As mudanças do leito do Rio Taquari, com o redirecionamento do mesmo para as partes mais baixas da planície de inundação, são mais constantes no lobo ativo, onde formam novos canais distribuídos com margens baixas e arenosas.

Os registros dos locais onde ocorreram os rompimentos dos diques marginais e que ocasionaram o traçado de novos distributários testemunham que esse é um fenômeno natural da dinâmica sedimentar do rio.

Cabe registrar que há uma prática antrópica esparsa, adotada pela população residente, na abertura de escavações dos diques marginais, abrindo canais artificiais de arrombados, como o fato documentado no trabalho de campo.

A bacia do Taquari, tanto no compartimento do leque aluvial como no setor do alto curso, situado no anfiteatro, registra uma dinâmica natural que vem modificando a paisagem, pelo expressivo aumento da sedimentação devido aos processos erosivos e setorialmente agressivos no baixo Taquari, por ações antrópicas de derruição nos planaltos sedimentários regionais pertencentes à Bacia do Alto Paraguai. Cabe mencionar que as enormes áreas utilizadas para pecuária e cultivo de grãos nos planaltos areníticos circundantes provocam a aceleração dos processos erosivos e, por conseguinte, aceleram o processo deposicional dos sedimentos no baixo curso do rio.

A observação das imagens de satélite das áreas do leque aluvial do Taquari, associadas aos relatos dos moradores, permite visualizar que grande parcela das propriedades e do sítio das colônias, atualmente, encontra-se submersa. Os impactos socioeconômicos e ambientais ocasionaram redução do rebanho bovino, migração da população tradicional para a zona urbana, principalmente para as cidades de Corumbá e Ladário (MS), aumento do isolamento por vias de comunicação terrestre e fluvial, dificuldade de locomoção com embarcações fluviais grandes para o transporte da produção da pecuária e da fruticultura.

A Colônia São Domingos tem inúmeros problemas carentes de soluções a curto e médio prazo. Pela complexidade que apresenta, pode ser considerada como um microcosmo, representante de um dos maiores problemas ambientais da mais complexa planície aluvial intertropical do planeta, e talvez o leque aluvial menos conhecido do mundo em termos de detalhes hidrogeomorfológicos.

$\mathrm{O}$ rol de problemas existentes, em virtude da alteração do canal do rio, é crítico e está a merecer um tratamento especial, haja vista que o isolamento físico e as condições de vida daqueles que bravamente lutam para permanecerem no local exibe um quadro de carência de planejamento adequado.
Há poucos registros sobre os episódios das alterações do curso do Rio Taquari ocorridos no leque aluvial, no decorrer do tempo geológico. Os esforços, integrados dos estudos vêm trilhando na esteira cientifica para minimizar os efeitos de um fenômeno natural, ora em processo de aceleração ocasionado pela falta de planejamento adequado para a exploração de recursos naturais dos setores que compõem a complexa bacia hidrográfica do Rio Taquari.

Agradecimentos à Fundação Manoel de Barros pelo apoio financeiro, à EMBRAPA/PANTANAL, pelo apoio, e à TV Pantanal da UNIDERP, pela realização do vídeo científico, denominado "Arrombados do Rio Taquari”.

\section{REFERÊNCIAS}

ABDON, M. de M. Os impactos no meio físico erosão e assoreamento na bacia hidrográfica do Rio Taquari, MS, em decorrência da pecuária. Tese - (Doutorado em Ciências da Engenharia Ambiental), USP, São Carlos, 2004.

AB'SABER, A. N. O Pantanal Mato-Grossense e a Teoria dos Refúgios. Revista Brasileira de Geografia: Reflexões sobre Geografia, Rio de Janeiro, v. 50, n. especial, 1988.

.CONGRESSOINTERNACIONALSOBRECONSERVAÇÃO DO PANTANAL, Campo Grande. Anais... Campo Grande, SEMA-MS, 1989. p. 108-112.

ALMEIDA, F. F. M. Geologia do Sudoeste Matogrossense. Boletim do D.N.P.M, n. 116, p. 1-118. 1945.

ASSINE, L. A., et al. Compartimentação geomorfológica, processos de avulsão fluvial e mudanças de curso do Rio Taquari, Pantanal Mato - Grossense. Revista Brasileira de Geomorfologia, Uberlândia, v. 6, n. 1, p. 97-108, 2005.

ASSINE, L.A; SOARES, P. C. Megaleques aluviais: uma discussão tendo como exemplo o leque do Taquari, Pantanal Mato-Grossense. In: CONGRESSO BRASILEIRO DE GEOLOGIA, Belo Horizonte. Anais... 1998.

BRAUN, E. H. G. Cone aluvial do Taquari, unidade geomórfica marcante da planície quaternária do Pantanal. Revista Brasileira de Geografia, Rio de Janeiro, v. 39, n.1, p. 164167, 1977.

CHRISTOFOLETTI, A. Geomorfologia fluvial. E. Blücher: São Paulo, 1988. v. 1.

CREPANI, E.; SANTOS, A. R. dos. Erosion of the upper Taquari basin and the sediment accumulation in the Pantanal Matogrossense. Resource and environmental monitoring, Rio de Janeiro, Sept. p. 26-30. 1994. 
MERCANTE, M. A. et al. Alterações causadas por avulsão no Rio Taquari...

CURADO, F. F. Caracterização dos problemas relacionados aos arrombados na Bacia do Rio Taquari. Relatório final da Embrapa - Pantanal. Mar. 2004. Disponível em: <www.ana. gov.br/gefap/>. Acesso em: 3 /4/ 2006.

MORETTI, S. A. L. As transformações recentes em uma comunidade tradicional no Pantanal Mato-Grossense da Colônia São Domingos. In: II SIMPÓSIO SOBRE RECURSOS NATURAIS E SOCIOECONÔMICOS DO PANTANAL. Anais... Corumbá, 1996. p. 179.

PADOVANI, C. R.; PONTARA, R. C.; PEREIRA, J. G. Mudanças recentes de leito no baixo curso do Rio Taquari, no Pantanal Mato-Grossense. Boletim Paranaense de Geociências, Curitiba, Ed. UFPR, n. 49, 2001.

QUEIROZ NETO, J. P. Pantanal, Pantanais: Patrimônio Nacional. In: RIBEIRO, W. C. Patrimônio Ambiental Brasileiro. São Paulo: Edusp, 2004. p. 284-301.

ROSS, J. L. S. Geomorfologia Ambiental. In: CUNHA, S. B. da; GUERRA, A. J. T. (Org.). Geomorfologia do Brasil. 3. Ed. Rio de Janeiro: Bertrand, 2003. p. 351-388.

SANTOS, E. et al. Impactos socioeconômicos e ambientais relacionados aos "Arrombados" no baixo curso do Rio Taquari. In: XI SIMPÓSIO BRASILEIRO DE GEOGRAFIA FÍSICA APLICADA. Anais... São Paulo, 2005, p. 113.
SOARES, A. P.; SOARES, P. C.; ASSINE, M. L. Areias lagoas do Pantanal, Brasil: herança paleoclimática? Revista Brasileira de Geociências, v. 33, n. 2, Jun. 2003.

SOUZA, O. C. Modern geomorphic processes along the Taquari river in the Pantanal: a model for development of a humid tropical alluvial fan. 1998. 135 p. Tese (Doutorado em Ecologia, Evolução e Biologia Marinha) - University of Califórnia, Santa Barbara.

TRICART, J. El Pantanal: um ejemplo Del impacto geomorfológico sobre el ambiente. Informaciones Geograficas, Chile, v. 29 , p. $81-98,1982$.

\section{JORNAIS}

Correio do Estado: 3 set.1991; 5 jun.2004.

Jornal da Cidade: 13 ago.1999; 5 fev. 2004.

Folha de São Paulo: 6 out.1997.

O Globo: 23 nov.1997. 